\title{
STABILITY ANALYSIS OF GLOBE VALVE USING CLASSICAL TECHNIQUES
}

\author{
ABORISADE DAVID OLUGBENGA ${ }^{1}$, OKELOLA MUNIRU OLAJIDE ${ }^{1}$, \\ ADEWUYI PHILIP ADESOLA ${ }^{2 *}$ \\ ${ }^{1}$ Department of Electronic and Electrical Engineering, Ladoke Akintola University of \\ Technology, Ogbomoso, Nigeria \\ ${ }^{2}$ College of Engineering, Bells University of Technology, Ota, Nigeria
}

\begin{abstract}
The importance of globe valve in fluid handling and control cannot be overemphasized. It is useful in oil and gas applications. If globe valve is not properly modelled, its primary purpose of regulation of fluid flow may be defeated. In this work, model of globe valve is developed from basic mechanical principles. The resulting model is a second order system whose response to a step input signal gives no overshoot. Further stability analysis with bode plot, Nyquist plot and root locus plot give a stable system indicating that the developed globe valve model is suitable for relevant areas of application.
\end{abstract}

Keywords: globe valve, stability analysis, classical techniques, bode, Nyquist, root locus

\section{INTRODUCTION}

Valves are mechanical devices used purposely for the control of fluid flow and pressure within a system. Valves are essential components of a piping system that transports vapors, slurries, liquids, gases, and other products. The primary roles of valves are to; stop and start flow, reduce, or increase a flow, control the direction of flow, regulate a flow or process pressure, and relieve a piping system of a certain pressure [1].

Globe valve could be used to start, stop and regulate flow of fluid. Its working motion is linear [2].

The working principle of globe valves involves three stages; fully open stage, throttling stage, and fully closed stage. As the handle wheel is rotated in clockwise direction, valve and steam plug move in downward direction across the fluid flow line. The valve plug travels down slowly to take its place between the two valve seats that are fixed. Once the valve plug has reached the fixed seats and the gap between the valve plug and seats is fully closed, fluid flow is completely prevented. Globe valves are of two basic design types. Plug and seat design and a quarter turn valve in which ball or disc or cone turns against the seat. Internally, globe valve has trim which is a part that is responsible for flow control. It is this trim position that the actuator controls which determines its open and close position [3].

Globe valve's common application is for isolation and throttling services. It has a good shut-off ability and it is available in tee, wye, and angle configurations. However, it performs poorly under low pressure, demand for greater force or throttling during shut-off operation to seat the valve and consumes very large energy $[4,5]$. Due to stem bending issues, leakage as a result of packing deterioration and manual operation by hand wheel is stressful and affects optimal efficiency [6]. This paper addresses modelling and subsequent stability testing of the developed

\footnotetext{
* Corresponding author, email: solaadewuyi@gmail.com

(C) 2020 Alma Mater Publishing House
} 
globe valve using classical stability analysis techniques, specifically; bode plot, Nyquist stability criterion, and root locus stability analysis technique. The rest of the paper contains literature review, methodology, results and discussion, and conclusion.

\section{LITERATURE REVIEW}

Problem of cavitation is prevalent in globe valve and numerical analysis has been used to investigate the effect of trims on the intensity, formation region and start point of cavitation. Results obtained showed improvements in valve performance with one or two trims. The number of trims has to be restricted purely on cost factor especially, when the trims are more than three [7]. In [8], "cavitation occurs when the local pressure drops below the saturation pressure. Phase transformation occurs and bubbles formed by vapor emerge, grow and finally collapse with the pressure rising again, thus leading to vibration, noise and erosion in the valve body as well as other piping equipment."

For straight pattern globe valve, flow reaches the center of the valve containing seat and plug. As the fluid is made to rotate at 90-degree inside the globe valve upstream and downstream of the valve plug, cavitation is generated. If this rotation of fluid continues, pressure drops below the vapor pressure making the vapor press out of the fluid. The resulting bubbles gain the lost pressure in the column and collapse creating pressure waves that could damage the seat, plug and body of the globe valve [9]. Therefore, cavitation leads to erosion in the trim, that is, the seat and plug, loud operational noise, strong vibration, change in fluid properties and plant shut down [10].

Oscillation problem has also been identified in pilot tube of the downstream pipeline. Some factors were established that could cause oscillation, such as choking flow, dead bands, and self-excitation of the moving component in valve [11]. To solve oscillation problem, a resistance to flow that is linear in characteristic was introduced through orifice and installation of porous material. This led to reduction in outlet area that suppressed cavitation. Also, cavitation, vortex shedding, turbulence and pressure pulsation were identified as the causes of vibration in valves [12].

In order, to mitigate some of these identified problems associated with globe valve, sine mechanism drive was used to achieve the quick opening function of valve to control the contact and separation between the O-ring and the end face of the valve [13]. Attempt to solve manual operation and controlling of fluid using modelling, simulation, and analysis approach with Computational Fluid Dynamics (CFD) software was carried [14]. CFD has also been used as a tool for predicting coefficient of various types of valve, globe valve inclusive [15]. However, CFD analysis is not enough to give full fluid characteristics due to high pressure produced by the fluid. This highpressure results into a nonlinear system behavior that affects the structure of globe valve [16].

Meanwhile, in order, to solve the problem of large energy consumption, a Pilot-Control Globe Valve (PCGV) which uses a pressure difference between the main valve and pilot valve as a means of control to make its operation faster was developed. It has been affirmed that PCGV is a novel valve that is quick in operation. It makes use of the pressure difference before and after the valve core to control the open and close state of the main valve. This PCGV spring must be chosen correctly to avoid operational time lag [17].

\section{MODELLING OF GLOBE VALVE WITH LINEAR CHARACTERISTICS}

The physical structure of globe valve is represented by Figure 1 (a) that comprises of the spring, k, the damper, B, and the mass, $M$ which are the energy storage elements of the globe valve. Figure 1 (b) and Figure 1 (c) show the forces involved due to external reaction, $F_{e}$ during the operations of globe valve as given by equation (1). The thrust due to internal reaction, $F_{i}$ is the force acting over the diaphragm area, $A_{d}$, the stem area, $A_{s}$ and the pipe wall area, $A_{w}$. This thrust is given by equation (2).

$$
\begin{gathered}
F_{e}=F_{M}+F_{B}+F_{K} \\
F_{i}=P_{i} \times\left(A_{d}-A_{s}-A_{w}\right)
\end{gathered}
$$

where $F_{M}$ is the inertia force due to mass of diaphragm and stem. According to Newton's second law of motion, the inertia force would be equal to the product of mass and acceleration according to equation (3). 


$$
F_{M}=\operatorname{Ma}(t)
$$
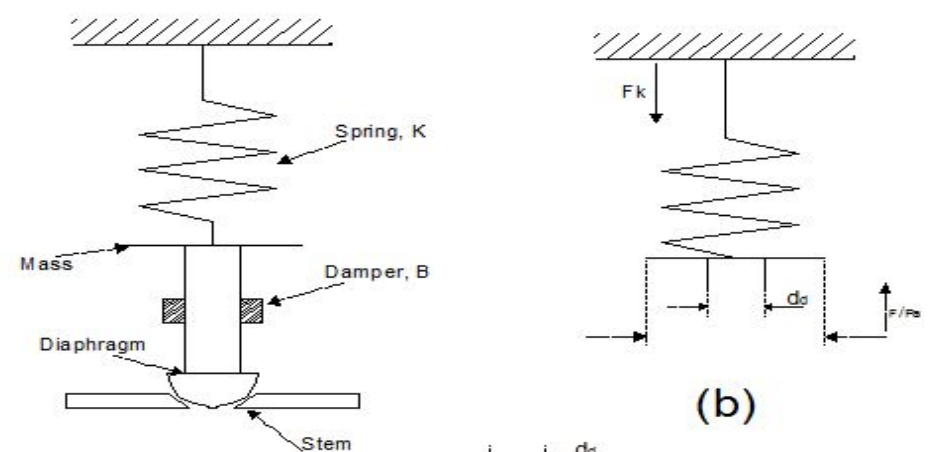

(b)

(a)

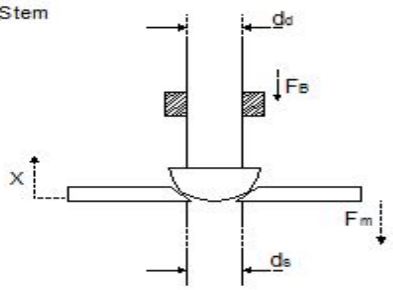

(c)

Fig. 1. Forces acting on globe valve system.

In terms of velocity, equation (3) is written as equation (4).

$$
F_{M}=M \frac{d v(t)}{d t}
$$

In terms of displacement, equation (4) becomes:

$$
F_{M}=M \frac{d^{2} x(t)}{d t^{2}}
$$

For the damping force, $F_{B}$, it is assumed that the $F_{B}$ is proportional to the velocity as shown in equation (6).

$$
F_{B}=B v(t)
$$

Equation (6) is written in terms of displacement, $\mathrm{x}$ as equation (7).

$$
F_{B}=B \frac{d x(t)}{d t}
$$

where $\mathrm{B}$ is the damping coefficient.

$F_{K}$ is the spring force which stores the potential energy. The restoring force of a spring is proportional to the displacement, $\mathrm{x}$ as presented by equation (8).

$$
F_{K} \alpha x(t)=k x(t)
$$

In order, to formulate equations of forces, assuming the globe valve system is linear and in equilibrium, D'Alembert principle is applied which states that, "for any body, the algebraic sum of externally applied forces and the forces resisting motion in any given direction is zero."

That is: 


$$
\sum F=0
$$

Therefore:

$$
F_{e}=F_{i}
$$

That is:

$$
F_{M}+F_{B}+F_{K}=P_{i} \times\left(A_{d}-A_{s}-A_{w}\right)
$$

Assuming the fluid flow in the pipe-valve chamber is constant, area of the pipe wall, $A_{w}$ is negligible, acceleration due to gravity is negligible, there is no leakage in the valve seat and diaphragm/plug area, and that the pipe is horizontal, equation (12) holds.

$$
F_{M}+F_{B}+F_{K}=P_{i} \times\left(A_{d}-A_{s}\right)
$$

Substituting equations (5), (7), and (8) in equation (12) results into equation (13).

$$
\left(M_{s}+M_{d}\right) \frac{d^{2} x(t)}{d t^{2}}+B \frac{d x(t)}{d t}+K x(t)=P_{i} \times\left(A_{d}-A_{s}\right)
$$

where $M=\left(M_{s}+M_{d}\right)$.

Apply Laplace transform to equation (13) assuming the system is a linear time invariant system, equation (14) results.

$$
M_{S} S^{2} X(S)+M_{d} S^{2} X(S)+B S X(S)+K X(S)=P_{i} \times\left(A_{d}(S)-A_{S}(S)\right)
$$

Therefore:

$$
\frac{X(S)}{P_{i}(S)}=\frac{A_{d}(S)-A_{S}(S)}{\left(M_{S}(S)+M_{d}(S)\right) S^{2}+B S+K}=G(S)_{V A L V E}
$$

Equation (15) is the equation that represent the transfer function of globe valve.

By substituting these parameters; Diaphragmarea, $A_{d}=0.132 \mathrm{~m}^{2}$, Stem area, $A_{s}=0.017 \mathrm{~m}^{2}$, Diaphragm mass, $M_{d}=0.087 \mathrm{~kg}$, Stem mass, $M_{s}=0.169 \mathrm{~kg}$, Damping Coefficient, $B=20 \mathrm{~N} / \mathrm{m} / \mathrm{s}$, and Spring Constant, $K=100 \mathrm{~N} / \mathrm{m}$, in equation (15), equation (16) results which is the transfer function, $G(S)_{V A L V E}$ of the developed globe valve.

$$
G(S)_{V A L V E}=\frac{0.149}{0.2562 S^{2}+20 S+100}
$$

\section{RESULTS AND DISCUSSION}

Figure 2 shows the open loop response of globe valve when a step input signal of $1.5 \times 10^{-3}$ is supplied. The curve has no overshoot and settles at 1.12 seconds as presented in Table 1. This display indicates that model of globe valve developed, a second order system, is critically damped. 


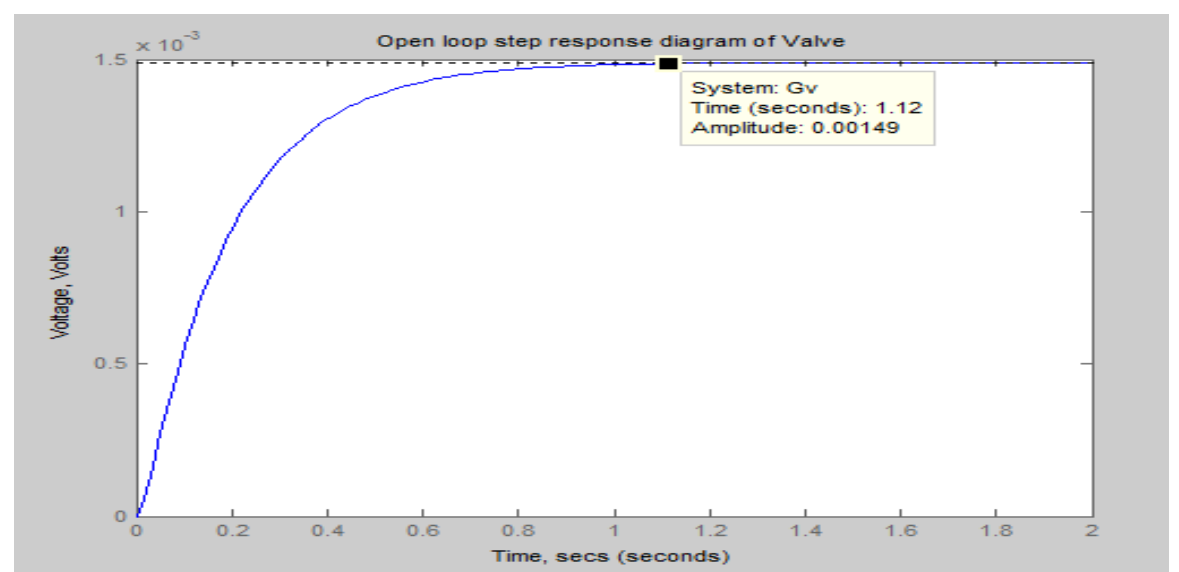

Fig. 2. Open loop response of globe valve to step input signal.

Table 1. System response to step input signal.

\begin{tabular}{cccc}
\hline System & Amplitude & Overshoot (\%) & Settling time (s) \\
\hline Globe Valve & 0.0015 & Nil & 1.12 \\
\hline
\end{tabular}

\subsection{Bode plot analysis}

The Bode plots analysis in Figure 3 shows the range of systems' stability limits in terms of gain and the phase margin. It shows that the investigated systems are stable and any reduction in gain and phase margin could lead to instability of the system. That is, considering the Bode plot of Figure 3, the globe valve operates below crossover frequency with negative feedback. For instance, a gain of magnitude $-104 \mathrm{~dB}$ at $301 \mathrm{rad} / \mathrm{s}$ operates at a phase angle of $-165^{0}$ which indicates that the system is stable because it does not operate in the crossover region of 1 and the phase is not in the positive feedback region.

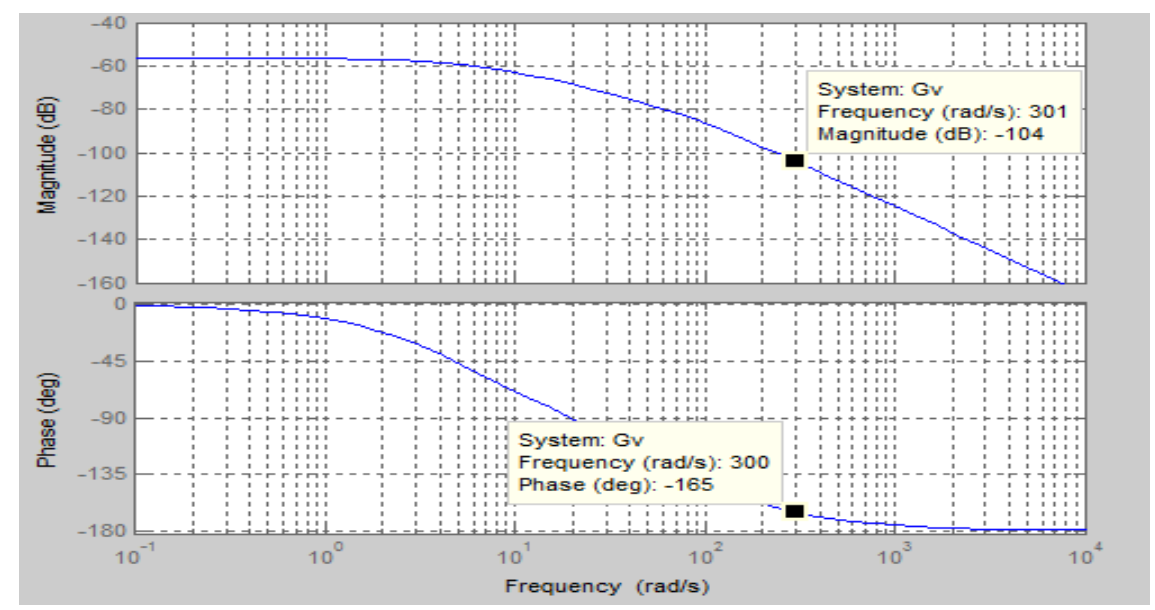

Fig. 3. Bode plot response of globe valve.

\subsection{Nyquist plot analysis}

The Nyquist plot of Figure 4 show the stability of the linearized feedback system and that the globe valve response is absolutely stable since the critical point, $(-1+j 0)$ lies outside the encirclement. 


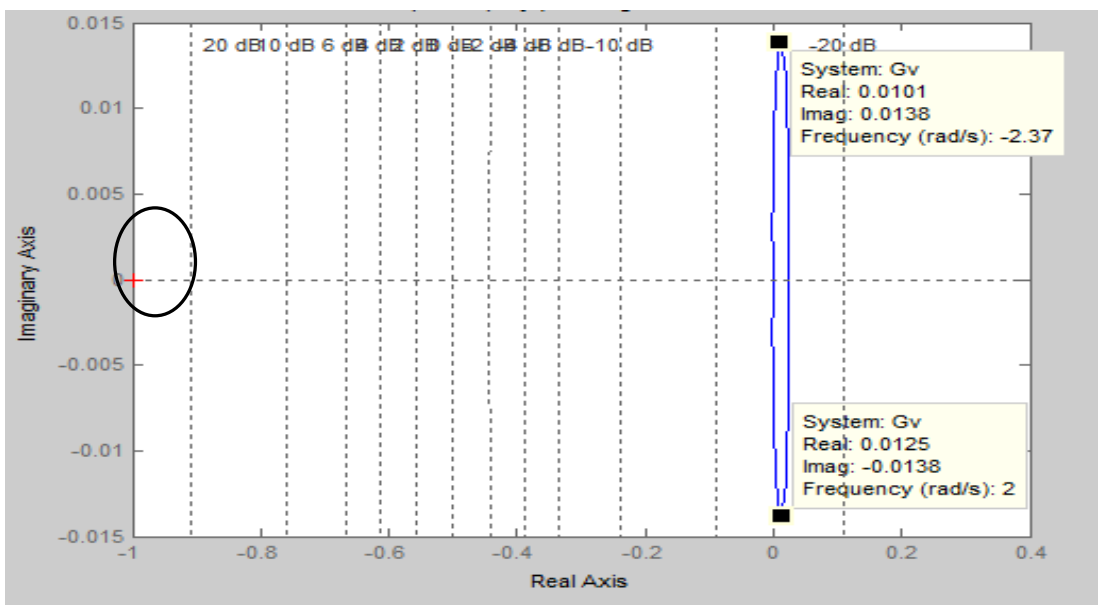

Fig. 4. Nyquist diagram of globe valve.

\subsection{Root locus analysis}

The root locus as presented in Figure 5 is also used to confirm the stability of the system models developed in the open loop configuration. The response show that globe valve system model developed is stable since it possesses no pole at the right hand side of the s-plane. Roots of the globe valve model developed, better approximate the behaviour of the systems and could be tagged the dominant roots.

The summary of results obtained using classical techniques are contained in Table 2.

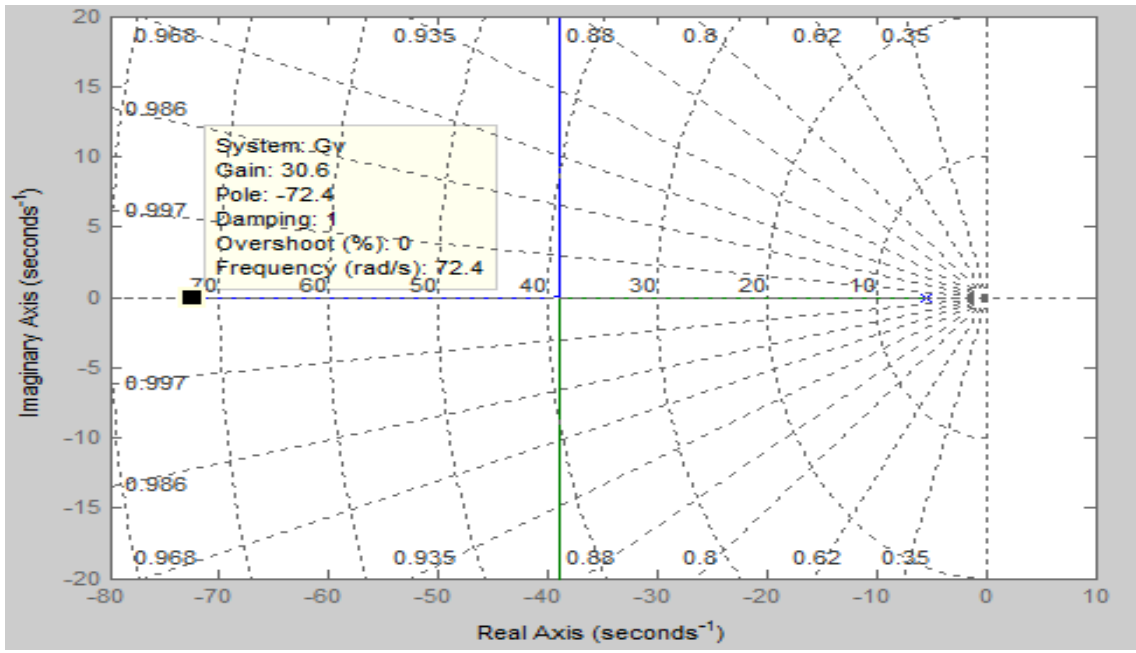

Fig. 5. Root locus characteristics of globe valve.

Table 2. Frequency Response Results of the Developed Systems

\begin{tabular}{llccccc}
\hline Method & System & $\begin{array}{c}\text { Gain } \\
\text { (dB) }\end{array}$ & $\begin{array}{c}\text { Frequency } \\
\text { (rad/s) }\end{array}$ & $\begin{array}{c}\text { Phase } \\
\left.\text { angle } \mathbf{(}^{\mathbf{0}}\right)\end{array}$ & Pole & $\begin{array}{c}\text { Critical } \\
\text { point }(\mathbf{- 1 + j 0 )} \\
\text { location }\end{array}$ \\
\hline $\begin{array}{l}\text { Bode } \\
\text { Plot }\end{array}$ & $\begin{array}{l}\text { Globe } \\
\text { valve }\end{array}$ & -104 & 301 & -165 & - & - \\
$\begin{array}{l}\text { Nyquist } \\
\text { Glot }\end{array}$ & $\begin{array}{l}\text { Globe } \\
\text { valve }\end{array}$ & - & - & - & - & $\begin{array}{c}\text { Outside the } \\
\text { encirclement }\end{array}$ \\
Root & Globe & 30.6 & 72.4 & - & -72.4 & - \\
Locus & valve & & & & & \\
\hline
\end{tabular}




\section{CONCLUSION}

This work has presented the mathematical model of globe valve from basic mechanical systems point of view. As a result of instability suffered by globe valve due to cavitation, it is important that globe valve model be analyzed using classical stability techniques such as bode plot analysis, Nyquist stability analysis, and root locus analysis. Results obtained from these analysis show that the developed globe valve, a second order system, is stable and gives stable response without an overshoot to the supplied step input signal. Therefore, this is a good starting point in the consideration of globe valve for diverse fluid handling and control applications.

\section{REFERENCES}

[1] Agarwal, V., Buttles, J.W., Beaty, L., Hallbert, B., Wireless online position monitoring of manual valve types for plant configuration management in nuclear power plants, IEEE Sensors Journal, vol. 17, no. 2, 2017, p. 311322.

[2] Choi, J., Park, S., Lee, K., Flow coefficient measurement of a globe valve for precision control, International Journal of Materials, Mechanics and Manufacturing, vol. 6, no. 4, 2018, p. 260-263.

[3] Asim, T., Mishra, R., Oliveira, A., Charlton, M., Effects of the geometrical features of flow paths on the flow capacity of a control valve trim, Journal of Petroleum Science and Engineering, vol. 172, 2019, p. 124-138.

[4] Qian, J., Liu, B., Jin, Z., Wang, J., Zhang, H., Lu, A., Numerical analysis of flow and cavitation characteristics in a pilot-control globe valve with different valve core displacements, Journal of Zhejiang University-SCIENCE A, vol. 17, no. 1, 2016, p. 54-64.

[5] Liu, B., Wang, J., Qian, J., Chen, F., Jin, Z., Dynamic response analysis of pilot control globe valve focusing on opening and closing time of pilot valve, Journal of Physics: Conference Series, vol. 745, 2016, p. 1-8.

[6] Benson, J., Rahul, V., Design and analysis of high pressure globe valve body with two element, International Journal of Innovations in Engineering and Technology, vol. 5, no. 4, 2015, p. 31-36.

[7] Yaghoubi, H., Madani, S.A.H., Alizadeh, M., umerical study on cavitation in a globe control valve with different numbers of anti-cavitation trims, Journal of Central South University, vol. 25, no. 11, 2018, p. 26772687.

[8] Qu, W.S., Tan, L., Cao, S.L., Xu, Y., Huang, J., Xu, Q.H., Experiment and numerical simulation of cavitation performance on a pressure-regulating valve with different openings, IOP Conferences Series: Materials Science and Engineering, vol. 72, 2015, p. 1-7.

[9] Sreekala, S.K., Thirumalini, S., Study of flow performance of a globe valve and design optimization, Journal of Engineering Science and Technology, vol. 12, 2017, p. 2403-2409.

[10] Sotoodeh, K., Selecting a butterfly valve instead of a globe valve for fluid control in a utility service in the offshore industry (based on an industrial experience), American Journal of Mechanical Engineering, vol. 6. no. 1, 2018, p. 27-31.

[11] Peng, J., Youn, C., Takeuchi, T., Kagawa, T., Stabilization of pilot valve system using linear flow resistance, Advances in Mechanical Engineering, vol. 9, no. 7, 2017, p. 1-9.

[12] Hussein, A.A., Experimental and numerical research on flow-induced vibration in valves, Al-Khwarizmi Engineering Journal, vol. 13, no. 2, 2017, p. 28-39.

[13] $\mathrm{Hu}, \mathrm{L}$. , A high degree of cleanliness of the electric air supply valve design, MATEC Web of Conferences, vol. 213, 2018, p. 1-7.

[14] Sonawanel, V.J., Rane, T.J., Monde, A.D., Vajarinkar, R.V., Gawade, P.C., Design and analysis of globe valve as control valve using CFD software, IOSR Journal of Mechanical and Civil Engineering, 2003, p. 63-71.

[15] Xiao-Ming, Z., Zhi-kun, W., Yi-Fang, Z., A simple method for high-precision evaluation of valve flow coefficient by computational fluid dynamics simulation, Advances in Mechanical Engineering, vol. 9, no. 7, 2017, p. 1-7.

[16] Pratik, P.N., Harshal, A.C., Design and FSI (Fluid Structure Interaction) analysis of globe valve: a literature review, International Journal of Engineering Research and Technology, vol. 3, no. 12, 2014, p. 599-601.

[17] Qian, J., Gao, Z., Wang, J., Jin, Z., Experimental and numerical analysis of spring stiffness on flow and valve core movement in pilot control globe valve, International Journal of Hydrogen Energy, vol. 42, no. 27, 2017, p. 17192-17201. 